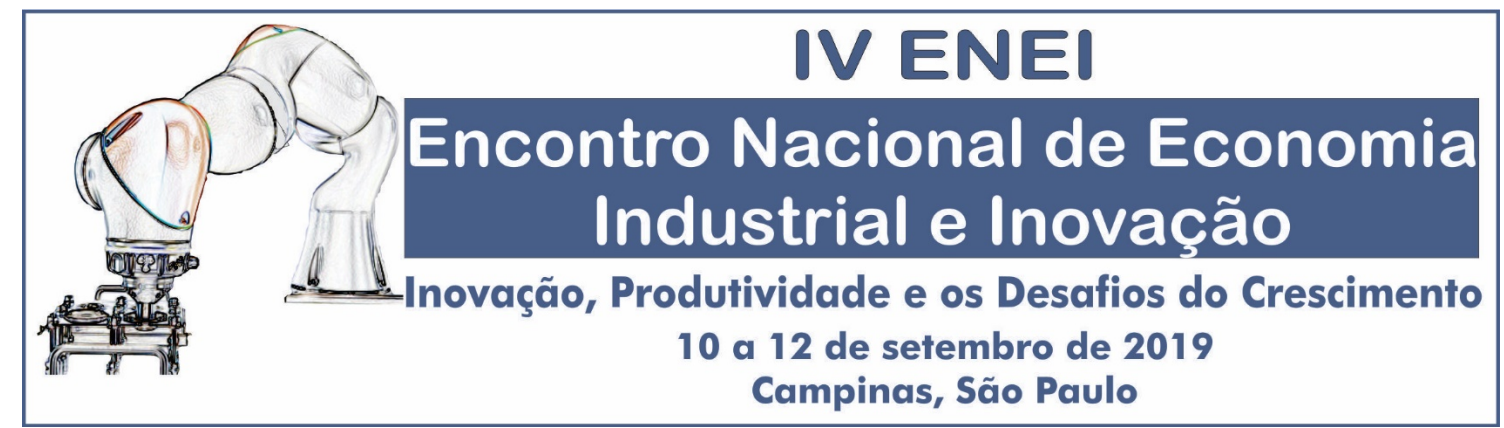

\title{
DESEMPENHO INOVATIVO NA INDÚSTRIA DE MÁQUINAS E EQUIPAMENTOS DA ECONOMIA BRASILEIRA
}

\author{
Gabriel Passos de Figueiredo*
}

Silvio Antonio Ferraz Cario**

Janaína Ruffoni***

Área de submissão ABEIN: 5.6 - Transferência de tecnologia e Processos de aprendizado. JEL: L69.

\section{RESUMO}

$\mathrm{O}$ artigo analisa o desempenho inovativo no setor de máquinas e equipamentos (M\&E) da economia brasileira a partir das características das inovações, atividades, resultados e fontes do conhecimento utilizadas. Informações são da Pesquisa de Inovação (PINTEC) de 2003, 2005, 2008, 2011 e 2014 . Foram observados ganhos de capacidade de desenvolvimento tecnológico de um seleto grupo de empresas, que impactaram o segmento. No plano dos processos produtivos, ocorreu avanço a partir de repasse tecnológico dos fornecedores, sendo referência o aumento do lançamento de "novos processos para o mercado nacional". Retomou-se a importância e o investimento em P\&D, assim como o aumento de lançamento de "novos produtos para o mercado nacional". Como alternativa as custosas aquisições de novas M\&E ou P\&D para desenvolvimento tecnológico, aumentou a busca por absorver conhecimento de diferentes fontes. Os resultados sinalizaram aprendizado via learning by doing, using, interacting, e a retomada do learning by searching.

Palavras-chave: Inovação, Máquinas e Equipamentos (M\&E), PINTEC.

\begin{abstract}
The article analyzes the innovative performance in the Brazilian machinery and equipament (M\&E) sector based in the characteristics of the innovaions, activies, results and knowledge sources used. The information from the innovations survey (PINTEC) for 2003, 2005, 2008, 2011 e 2014. Technological development capacity gains were observed in a select group of companies, which impacted the segment. Regarding production processes, the progress continues as a result of technological transfer of suppliers, despite the increase in the launch of "new processes for the domestic market". The importance and investment in R \& $\mathrm{D}$ has increased, just as the launching of "new products for the domestic market". As an alternative to the costly acquisitions of new M \& E or R \& D for technological development, have increased the search for absorbing knowledge from different sources. The results indicated learning through doing, using, interacting, and the resumption of learning by searching.
\end{abstract}

Key-words: Innovation, Machinery and Equipament (M\&E), PINTEC.

\footnotetext{
* Doutor em Economia junto ao Programa de Pós-Graduação em Economia da Universidade Federal de Santa Catarina (UFSC). E-mail: gabrielfigus@hotmail.com

** Doutor em Economia pelo IE/UNICAMP e Professor vinculado aos Cursos de Graduação e Pós-Graduação em Economia e Administração da Universidade Federal de Santa Catarina (UFSC). E-mail: fecario@yahoo.com.br

*** Doutora em Política Científica e Tecnológica pelo DPCT/UNICAMP, Professora Titular do Programa de Pós-Graduação em Economia da UNISINOS. E-mail: jruffoni@unisinos.com
} 


\section{INTRODUÇÃO}

Bens de capital são utilizados na produção de outros bens ou para contínua prestação de serviços. Sua demanda se caracteriza como investimento de outros setores econômicos, que demandam bens de capital para aumentarem a capacidade produtiva ou a produtividades de seus processos. Esta demanda aumenta não apenas a capacidade de produção das firmas, mas a Formação Bruta de Capital Fixo (FBCF) das economias. Potencializa, nestes termos, os efeitos multiplicativos do investimento e difundem progresso tecnológico ao longo das cadeias produtivas.

$\mathrm{Na}$ indústria de bens de capital existem tecnologias padronizadas de máquinas simples até sistemas complexos customizados intensivos em tecnologia para a produção de bens não existentes no mercado, produzidos sob-encomenda. Sendo assim, existe uma gama de segmentos produtores de bens de capital que incorporam tecnologia ao mercado, na medida que buscam atender a demanda de todo um sistema produtivo e de prestação de serviços.

As firmas produtoras de bens de capital delimitam-se em três gêneros: maquinaria elétrica, maquinaria mecânica (máquinas e equipamentos - M\&E) e de material de transporte, sendo que apenas o segundo é constituído exclusivamente por bens de capital (VERMULM; ERBER, 2002). No Brasil, para o ano de 2015, M\&E representou 10,5\% da produção industrial. Este percentual foi maior no início da década (acima de 13\%), em que a demanda agregada e a taxa de investimento se encontravam em ascensão.

$\mathrm{Na}$ teoria e na prática, os resultados tecnológicos (inovações) são derivados dos esforços e capacidades de as empresas absorverem, combinarem e desenvolverem conhecimento tecnológico. São realizados esforços de busca e transformação de conhecimentos e práticas que se desdobram em novas rotinas, capacidades e resultados no plano do desenvolvimento tecnológico. São desenvolvidas capacidades "dinâmicas" que reconfiguram as capacidades de as empresas absorverem, adaptarem e desenvolverem as novas tecnologias. Os processos de aprendizado, por sua vez, são mecanismos de transformação do conhecimento, que limitam ou potencializam o desenvolvimento das capacidades e suas respectivas inovações, dentro das trajetórias tecnológicas das empresas.

Por fornecer capacidade produtiva e difundir tecnologia, torna-se fundamental compreender as características das inovações do segmento de $M \& E$, as fontes de conhecimento utilizadas, suas capacidades e resultados tecnológicos. Considerando que os processos de aprendizado condicionam a trajetória e o desenvolvimento das capacidades, e assim, os resultados em inovação das empresas, a análise deve se aprofundar em entender como ocorrem e quais são os processos de aprendizado desenvolvidos na produção de M\&E.

Nestes termos, o objetivo do estudo é analisar o desenvolvimento inovativo do segmento de M\&E da indústria nacional, a partir da análise das características das inovações, fontes de conhecimento utilizadas, atividades empregadas e resultados tecnológicos, de forma a vincular com os processos de aprendizagem. Os dados foram da Pesquisa de Inovação (PINTEC) dos anos 2003, 2005, 2008, 2011 e 2014 do Instituto Brasileiro de Geografia e Estatística (IBGE).

Busca-se responder à pergunta: $\mathrm{O}$ desempenho inovativo na produção nacional de $\mathrm{M} \& \mathrm{E}$ tem demonstrado aumento das capacidades de desenvolvimento próprio de tecnologias, ou que se mantêm as necessidades do repasse tecnológico dos fornecedores? E, sob este quadro, como se manifestam os mecanismos de aprendizado tecnológico?

Para tal, o artigo contém cinco seções. Na segunda, é apresentada uma breve discussão sobre o processo de inovação, geração de capacidades tecnológicas, fontes de conhecimento e aprendizado das empresas. Na terceira, é feita uma contextualização dos padrões tecnológicos e de concorrência da indústria de bens de capital. Na quarta seção, é feita a descrição e análise dos dados. E, por fim, são apresentadas as conclusões.

\section{INOVAÇÃO, CAPACIDADES TECNOLÓGICAS, FONTES DE CONHECIMENTO E MECANISMOS DE APRENDIZAGEM}


A busca e o avanço tecnológico levam a rupturas tecnológicas marcadas por oportunidades econômicas com base no crescimento da produtividade (inovação em processo) ou na geração de novos mercados (inovação em produtos). Em meio as rupturas evoluem novos processos produtivos, novas empresas, organizações, outros produtos, até mesmo segmentos econômicos e novas relações sociais, na formação de um novo paradigma tecnológico e estrutura econômica.

As capacidades que as empresas apresentam em um paradigma/regime tecnológico podem, agora, não serem mais adequadas neste ambiente de concorrência dinâmica, em que as empresas se reposicionam em meio ao avanço tecnológico, de acordo com suas capacidades dinâmicas (tecnológicas), buscando explorar as oportunidades vigentes e potenciais (TEECE, 1986, 1994 e 2014).

Zahra et al (2006) destacam que três elementos devem ser esclarecidos, existe (1) a capacidade de a empresa resolver um problema (capacidade substantiva); (2) a presença da rápida mudança na fronteira de problemas (uma característica ambiental); e, (3) a capacidade de mudar a forma como a empresa resolve os seus problemas (uma capacidade dinâmica, de ordem superior, pois diz respeito a uma capacidade de alterar capacidades). O desenvolvimento das capacidades segue uma trajetória "dependente" do conhecimento acumulado pelas experiências e meios de aprendizados da empresa.

Assim, distingue-se capacidade substancial de capacidades dinâmicas. A primeira leva a resultados comuns, enquanto a segunda é capaz de alterar ou reconfigurar recursos e capacidades materiais existentes. Os resultados das capacidades dinâmicas diferem dos comuns, sustentando uma vantagem competitiva, que em grande parte se traduz em inovações (HELFAT; PETERAF, 2009). Desenvolver novos produtos é uma capacidade substantiva, enquanto a capacidade de reformar o modo de se desenvolvem novos produtos é uma capacidade dinâmica.

Wang e Ahmed (2007) identificam três componentes das capacidades dinâmicas que podem ser adotadas em um modelo de medição empírica: (i) capacidade de detecção (ou adaptação); (ii) capacidade de absorção; e, (iii) capacidade de inovação das empresas. A primeira diz respeito a capacidade de a empresa analisar e se adaptar as mudanças no ambiente dinâmico, utilizando os recursos disponíveis. A segunda diz respeito a como e de onde absorver conhecimento/tecnologia/processos externos e combinalos com as capacidades e conhecimento característicos internos. Capacidades de inovação dizem respeito a capacidade de desenvolver tecnologias em processo ou produto, radicais ou incrementais, ou mesmo organizacionais. Por sua vez, os meios de aprendizado são os responsáveis pela formação das diferentes capacidades geradas em uma empresa, potencializando ou impondo limites para a construção destas capacidades (TEECE, 1994 e 2014; LUNDVALL, 2001; TEIXEIRA et al, 2016).

Devido as constantes mudanças nos padrões produtivos, na configuração dos mercados e preferências dos consumidores, assim como com o surgimento cada vez mais intenso de novas tecnologias, o conhecimento de hoje pode não ter relevância para as atividades de amanhã, e tal velocidade na criação e destruição do conhecimento necessário para o desenvolvimento das atividades se imprime em uma necessidade constante de aprendizado (FERNANDES, 2008).

Sendo assim, a capacidade dinâmica tem que ser construída e reconstruída de forma permanente. Diante do desenvolvimento das particularidades das capacidades que a formam, encontra-se o processo de busca e rotina dentro das empresas, que colaboram para criar um ambiente propício ao aprendizado. Os meios de aprendizado potencializam ou impõem limites para a formação das diferentes capacidades geradas em uma empresa, dentre as quais as capacidades dinâmicas, seja de absorção de conhecimento, adaptação ou inovação (TEECE, 1994 e 2014; LUNDVALL, 2001; TEIXEIRA et al, 2016).

Considerando que os resultados no plano das inovações (que podem ser observados) são resultados das capacidades desenvolvidas pelas empresas, e estas capacidades (dentre as quais as dinâmicas, de complexa mensuração/observação) são influenciadas por processos de aprendizado desenvolvidos dentro de empresas e setores (mecanismos que podem ser analisados), é possível analisar os resultados tecnológicos (as inovações) a partir da perspectiva dos processos de aprendizado que possibilitam aquela transformação ou resultado, assim como as fontes das informações internas e externas utilizadas. Os meios de aprendizado originais são os contextualizado por Malerba (1992): learning by doing, learning by using, learning by searching, learning by interacting, learning from advances in science and technology e, learning from inter-industry spillovers. 
O mecanismo learning by doing (aprender fazendo) ocorre no ambiente interno à empresa, com o desenvolvimento das habilidades em meio as atividades produtivas. $\mathrm{O}$ aprendizado ocorre na prática e a partir do ato de fazer, construir um produto, e se dá principalmente no estágio de produção industrial. Isto gera um fluxo contínuo de modificações e inovações incrementais nos produtos e processos. Por outra via, nem todo o conhecimento foi codificado, se faz necessário a existência de conhecimento tácito no processo e/ou operação, de modo que haja desenvolvimento crescente das habilidades de produção.

Tanto usuários como fabricantes aprendem por meio do learning by using (aprender usando). O uso de $M \& E$, matérias-primas e produtos gera conhecimentos e capacidades que permitem melhorias no produto e no processo. O usuário aprende sobre o produto e os processos enquanto retornam aos produtores informações pertinentes que podem ser utilizadas para melhora do desempenho. Rosenberg (2006) destaca a importância deste processo para a produção de bens de capital, uma vez que as características de um bem de capital durável não podem ser entendidas antes de uma prolongada experiência de uso do equipamento. Principalmente para a produção sob-encomenda, de um produto singular produzido de acordo com as necessidades dos clientes, a utilização traz aprendizado e conhecimento que retorna as linhas produtivas.

O learning by searching também ocorre em ambiente interno a empresa através da formalização de atividades ligadas ao desenvolvimento tecnológico que faz gerar novos conhecimentos, como é o caso da P\&D. O monitoramento, atividades para o desenvolvimento e a busca de tecnologias geram novos conhecimentos e ampliam as capacidades para inovar. O esforço direcionado para este desenvolvimento tecnológico possibilita as empresas traçarem suas próprias trajetórias, desenvolvendo seus próprios produtos e processos para produzi-los.

O learning by interacting (aprendizado por interação) combina o aprendizado que acontece dentro da própria fábrica (learning by doing) com aqueles que ocorrem com consumidores e fornecedores (learning by using). O ponto central é a interatividade entre produtor e consumidor. O aprendizado aqui se dá em decorrência da troca de informações entre usuário e produtor, mas também ocorre por via de relações com universidades e outros atores e permitem gerar conhecimento. Tal forma de aprendizado tem sido cada vez mais utilizada por setores de alta tecnologia, onde os serviços de suporte para o melhoramento do produto são constantes e importantes para o sucesso competitivo das empresas.

O learning from advances in science and technology (avanço na ciência e tecnologia) ocorre por via de fontes externas à empresa. Este mecanismo consiste em absorver e aprender com o avanço da ciência $\mathrm{e}$ tecnologia. Novos produtos, materiais, conhecimento ou transformações realizadas por outras empresas, em universidades ou mesmo em outros setores industriais podem ser aplicados e utilizados. Por se tratar de um conhecimento ou informação externa, todas as empresas podem se beneficiar, mas depende das capacidades de aprendizado individual da firma melhor absorver e utilizar este conhecimento para seus devidos fins. Descobertas em universidades normalmente são públicas e possibilitam o aprendizado e inovação a partir do avanço deste conhecimento.

O learning from inter-industry spillovers também ocorre em ambiente externo à empresa. Trata-se de conhecer o que os competidores e outras firmas da indústria estão fazendo em termos de dinâmica produtiva, processos inovativos - produtos e processos e resultados alcançados, de forma direcionar o desenvolvimento e a busca tecnológica da firma. Esse aprendizado é derivado do reconhecimento do ambiente no qual está inserida a firma, que pode acarretar um conjunto de externalidades positivas e, consequentemente, melhoramentos em produtos e processos.

Os processos de aprendizado estão relacionados tanto ao ambiente interno como externo da empresa, e diferem com relação aos processos de absorção do conhecimento, utilização e resultados possíveis de serem alcançados (FERNANDES, 2008). Cohen e Levinthal (1994), Zahra e George (2002) e EasterbySmith et al (2005) já destacavam a capacidade de absorção como fundamental aspecto da capacidade dinâmica. Trata-se das capacidades de adquirir, absorver, transformar e explorar o conhecimento interno e externo, de acordo com o interesse da empresa.

Diferentes padrões de capacidade de absorção de conhecimento se relacionam com distintos tipos de conhecimento, diferentes fronteiras de atuação, agentes ou fontes pelo qual o conhecimento é absorvido. Para cada tipo especifico de conhecimento, se diferenciam os processos de aprendizado, assim como os resultados passíveis de ocorrerem. Uma empresa deve apresentar capacidades de absorver informações de 
fornecedores de $M \& E$, materiais, componentes, clientes e concorrentes, da mesma indústria ou adjacentes, universidades, dentre uma diversidade de fontes de informações (MUROVEC; PRODAN, 2009).

Nestes termos, ganha importância entender e cruzar os processos de aprendizado, as fontes do conhecimento absorvido, junto aos diferentes resultados possíveis de se alcançar. Nos mercados modernos as empresas dependem cada vez mais do conhecimento de parceiros e da cadeia de fornecedores para identificar o conhecimento externo e convertê-lo em valor para a empresa, uma firma absorve conhecimento e técnicas com fornecedores que vai impactar principalmente a inovação em seus processos produtivos. O mesmo ocorre com os feedbacks dos clientes, sobre a utilização dos produtos e necessidades do mercado, que vão direcionar o desenvolvimento tecnológico dos produtos (SAENZ et al, 2014).

Azedegan (2011) identifica a associação positiva entre capacidade de inovação e o desempenho na gestão da rede de fornecedores, que conforme Saenz et al (2014) é potencializada pela compatibilidade organizacional e de conhecimento entre os parceiros. Nas relações com os parceiros (clientes e fornecedores), não apenas a empresa atinge vantagem competitiva, mas o grupo de empresas que se relacionam podem construir uma "vantagem colaborativa" (CHEN; PAULRAJ, 2004). Neste quadro, Rosa e Ruffoni (2014) consideram importante a interação Universidade-Empresa, que possibilitam a melhora nos processos ou potencialize a realização de inovações conforme o nível de capacidade de absorção de conhecimentos externos destas empresas.

A abordagem das capacidades dinâmicas, mecanismos de aprendizado, fontes de conhecimento e resultados em inovações constitui referencial para análise de como a tecnologia é absorvida e/ou repassada de/para outras empresas e instituições (tecnologia exógena), a partir de relações com fornecedores, clientes, universidades e outros agentes; e/ou, desenvolvidas pela própria empresa (tecnologia endógena), que ocorre nas relações de produção, projetos, departamentos de P\&D; ou, a partir da combinação do conhecimento externo com o conhecimento interno. Não apenas os resultados e as capacidades no plano das inovações importam, mas os processos de aprendizado e as fontes de informação para absorção do conhecimento, que possibilitarão, portanto, as diferentes transformações e resultados tecnológicos.

\section{PADRÃO DE INOVAÇÃO E CONCORRÊNCIA DA INDÚSTRIA DE BENS DE CAPITAL}

Os bens de capital são utilizados continuadamente nos processos produtivos, sem que haja sua transformação, como ocorre com outros insumos. Outros setores econômicos demandam bens de capital para que possam produzir, portanto, a aquisição de bens de capital caracteriza-se como um investimento produtivo ou para geração de capacidades de prestação de serviços.

Destaca-se o papel de difusora de progresso tecnológico desta indústria, visto que participa de todas as cadeias produtivas. Por outro lado, a presença de um setor doméstico produtor de bens de produção aumenta os efeitos de encadeamento para trás e o efeito multiplicador de expansão primária dos gastos autônomos na economia, ampliando o mercado interno e o potencial de geração de emprego e renda. Quando uma nação importa considerável proporção de seus bens de capital, parte dos efeitos positivos de retroalimentação dos investimentos é desviada para o exterior (ALÉM; PESSOA, 2005).

As firmas produtoras de bens de capital delimitam-se em três gêneros: maquinaria elétrica, maquinaria mecânica (M\&E) e de material de transporte. Apenas o segundo constituído representa exclusivamente bens de capital (VERMULM; ERBER, 2002). Na indústria de bens de capital são produzidos $\mathrm{M} \& \mathrm{E}$ - associados à indústria mecânica - e ônibus e caminhões - referentes à indústria de material de transporte. A fronteira tecnológica encontra-se na mecatrônica, ocorrendo nas últimas décadas uma profunda incorporação da eletrônica na produção e nos produtos da indústria mecânica (M\&E). A ampliação do conteúdo eletrônico e de software na produção do setor elevou, ainda mais, a já existente heterogeneidade entre os fabricantes no conjunto produtivo de M\&E (ALÉM; PESSOA, 2005).

No plano interno das firmas, os determinantes da produção se expressam segundo suas especificações técnicas (padrões tecnológicos de produção), onde a produção ocorre de forma seriada ou sob encomenda. Os bens de capital seriados são produzidos em escala (ou em série), com relativa padronização de projetos, uma vez que a produção se relaciona com tecnologias mais maduras (dominadas). Tal padrão produtivo exige plantas industriais rígidas e mão-de-obra especializada. Levando em conta os 
níveis de amadurecimento tecnológico, a engenharia ocorre em processo, fazendo com que a busca por produtividade, eficiência produtiva, redução de custo e aumento da qualidade sejam fontes dinâmicas de capacidade competitiva. Quanto mais madura e difundida for a tecnologia em processo envolvida na produção, mais o preço torna-se determinante na definição da dinâmica da concorrência do mercado, apesar de a qualidade e os serviços de assistência técnica continuarem como outros elementos competitivos. Os investimentos seguem na direção da ampliação da capacidade instalada, e as inovações são incrementais e em processo, mesmo que seja alta a incidência de inovações em produto (BERTASSO, 2009)

Por outra via, a produção de bens de capital sob encomenda apresenta características técnicas singulares a cada projeto, que muitas vezes têm a utilização definida pelas necessidades dos clientes. Este padrão abrange uma gama de equipamentos flexíveis, de sofisticação tecnológica e mão-de-obra com qualificação capaz de desenvolver tecnologias distintas do padrão. A engenharia reversa e a inovação em produtos se destacam na definição do padrão produtivo. A concorrência ocorre através da personalização e diferenciação produtiva. Investimento em aprendizado, treinamento e P\&D tornam-se eixo motor de competências tecnológicas e competitivas para tais empresas (BERTASSO, 2009).

Araújo (2011), classificando a produção de M\&E de acordo com a taxonomia de Pavitt (1984), Campos e Urraca (2009) e Silva e Suzigan (2014), considera o setor de bens de capital como de "fornecedores especializados" (specialised suppliers). Pela taxonomia de Marsili e Verspagen (2001), Gonçalvez e Yonamini (2013) consideram como regime de engenharia de produto. Contudo, Araújo destaca características que os aproximam também das outras categorias de classificação. A fabricação de bens de capital seriados é, em parte, intensiva em escala (scale intensive), enquanto, a fabricação de bens de capital sob encomenda resulta em produtos singulares, e pode definir suas próprias trajetórias tecnológicas (science based). Isso demonstra uma relativa heterogeneidade na fabricação de Bens de Capital.

No plano macroeconômico, outros determinantes impactam o setor. O desempenho da indústria de bens de capital - e M\&E - é pró-cíclico, condicionado pelo ciclo de investimento da economia. Apenas após os setores econômicos se utilizarem da capacidade ociosa instalada ou desejarem modernizar suas instalações, demandarão $M \& E$, sendo necessários crescimento e estabilidade econômica para que haja demanda sustentada ou investimento. Vermulm (2003) salienta o caráter instável da demanda de M\&E pelo forte componente expectacional nas decisões de investimento, e que bens de capital são ativos de baixa liquidez e de retorno em um horizonte de longo prazo.

Vermulm e Erber (2002) mencionam dentre outras variáveis macroeconômicas, o juro e o câmbio como variáveis essenciais na definição da competitividade do setor em economias abertas. O juro condiciona o financiamento da produção e comercialização das M\&E. O câmbio, se valorizado, viabiliza a modernização produtiva, facilitando a aquisições de M\&E e compras no mercado internacional; se desvalorizado, encarece a modernização e diminui as importações de $M \& E$, protegendo produtores nacionais e estimulando setores econômicos vinculados.

De uma forma geral, as expectativas futuras de crescimento dos diversos setores econômicos contribuem para o desempenho da produção de M\&E. O ambiente de crescimento econômico estável estimula a expansão e o desenvolvimento do setor. Por outro lado, recessões e um ambiente econômico instável causam incertezas que influenciam nas expectativas futuras, ocasionando efeitos negativos à indústria de bens de capital. Máquinas e equipamentos são ainda mais sensíveis às oscilações do mercado por figurarem exclusivamente como bens de capital; mais especificamente, o segmento de máquinas sob encomenda é impactado de forma mais intensiva, uma vez que as expectativas e a duração dos projetos relacionam-se com condições de longo prazo e de complexidade tecnológica maior (VERMULM, 2003).

\section{ANÁLISE DAS INOVAÇÕES, FONTES DE CONHECIMENTO, DESENVOLVIMENTO TECNOLÓGICO E PROCESSOS DE APRENDIZADO NA INDÚSTRIA DE MÁQUINAS E EQUIPAMENTOS NACIONAL}

A produção nos diversos setores produtivos ou mesmo de prestação de serviço na economia não ocorre sem a utilização de bens de capital ou M\&E que possibilitem as operações. Quando ocorrem mudanças na produção dos segmentos que demandam M\&E, os produtores das M\&E devem se adaptar ou 
desenvolver sua produção conforme as transformações da demanda, e em muitos casos são os produtores de M\&E os próprios fornecedores das novas tecnologias para produção em outros setores da economia. Trata-se de um setor que se relaciona com uma gama de outros setores e com o processo de transformação das tecnologias dentro destes. Sendo assim, é natural observar em M\&E uma elevada taxa de empresas inovadoras (proporcional de empresas que inovaram, em produto e/ou processo, em relação ao total de empresas do setor), devido a exigência do mercado por desenvolvimento de novas M\&E e processos para produção.

Por outro lado, apesar de acima da média da indústria de transformação, extrativa, eletricidade/gás e serviços, em meio a indústria de transformação o segmento de $M \& E$ posicionou-se na $7^{\mathrm{a}}$ posição no ranking dos setores com maiores taxas (proporcional) de empresas inovadoras no período de 2012-14, conforme dados da PINTEC (2014) ${ }^{1}$. Esta posição não é baixa, se considerarmos as características dos setores acima no ranking, em sua maioria naturalmente envolvidos com o lançamento de novos produtos no mercado, com alta ou baixa intensidade tecnológica (exemplos de dois extremos: indústria eletrônica e de alimentos). Os segmentos da indústria nacional de transformação com maiores proporcionais de empresas inovadoras, para o período de 2012-14, foram: (i) produção de equipamentos de informática, eletrônicos e ópticos; (ii) farmoquímicos e farmacêuticos; (iii) produtos químico; (iv) máquinas, aparelhos e materiais elétricos; (v) produtos alimentícios; (vi) fabricação de móveis; e, (vii) máquinas e equipamentos.

Tabela 1 - Segmentos com mais elevada taxa de empresas inovadoras com relação ao total das empresas, na indústria e serviços, Brasil, 2009 a 2014*.

\begin{tabular}{|c|c|c|c|c|}
\hline \multirow[b]{2}{*}{ Atividades da indústria e serviços } & \multicolumn{2}{|c|}{$2009-2011$} & \multicolumn{2}{|c|}{$2012-2014$} \\
\hline & Total & $\begin{array}{c}(\%) \text { de } \\
\text { empresas } \\
\text { inovadoras }\end{array}$ & Total & $\begin{array}{c}(\%) \text { de } \\
\text { empresas } \\
\text { inovadoras }\end{array}$ \\
\hline Total & 128699 & 36 & 132529 & 36 \\
\hline Indústrias extrativas & 2421 & 19 & 2708 & 42 \\
\hline Indústrias de transformação & 114212 & 36 & 115268 & 36 \\
\hline Produtos alimentícios & 14013 & 41 & 13846 & 45 \\
\hline Produtos químicos & 3517 & 59 & 3632 & 50 \\
\hline Farmoquímicos e farmacêuticos & 458 & 54 & 406 & 52 \\
\hline Equip. de informática, eletrônicos e ópticos & 1618 & 59 & 1542 & 68 \\
\hline Máquinas, aparelhos e materiais elétricos & 2201 & 44 & 2170 & 47 \\
\hline Fabricação de máquinas e equipamentos & 6228 & 41 & 6588 & 40 \\
\hline Outros equipamentos de transporte & 530 & 65 & 598 & 38 \\
\hline Fabricação de móveis & 5799 & 45 & 6168 & 44 \\
\hline Eletricidade e gás & 503 & 44 & 468 & 29 \\
\hline Serviços & 11564 & 37 & 14085 & 32 \\
\hline $\begin{array}{l}\text { Atividades dos serviços de tecnologia da } \\
\text { informação (produção de software) }\end{array}$ & 3695 & 45 & 5043 & 46 \\
\hline Pesquisa e desenvolvimento & 25 & 95 & 20 & 90 \\
\hline
\end{tabular}

Fonte: Elaboração própria, dados PINTEC (2011 e 2014).

* Esta tabela contou com apenas duas publicações da PINTEC, com fins de comparar as taxas de empresas inovadoras entre os principais segmentos nos últimos anos de análise, não sua evolução.

No segmento produtor de M\&E em específico, no período entre 2001-03 e 2003-05, a força do movimento das inovações foi em produtos $(75,7 \%$ das empresas inovadoras). O período foi marcado pelo aumento do número de empresas $(7,2 \%)$, com redução do número de empresas inovadoras $(-3,1 \%)$. Isto levou a redução da taxa de empresas inovadoras de 43,5\% para 39,4\%, conforme dados da Tabela 2.

\footnotetext{
${ }^{1}$ Por ser realizada a cada 3 anos, e por analisar as informações das empresas ao longo deste período, os dados e publicações da PINTEC dizem respeito a janelas de tempo de 3 anos. Por esta razão, as janelas temporais das tabelas são de 2001-2003, 20032005, 2006-2008, 2009-2011 e 2012-2014.
} 
No plano dos dispêndios (visível na Tabela 3), entre 2003 e 2005, ocorreu um salto nos gastos/investimentos com a aquisição de outros conhecimentos externos e absorção das inovações tecnológicas introduzidas no mercado. Tal ocorrência sinalizou o movimento das empresas imitadoras em busca da atualização/absorção tecnológica, cópia/produção de outros produtos, em vista que a concentração das inovações foi em produtos "Novos para as empresas", e não "Novos para o mercado nacional" (dados visíveis na Tabela 2).

Entre 2003-05 e 2006-08, a tendência foi inversa, com redução no número de empresas do setor ($4,3 \%)$, apesar do aumento no número de empresas inovadoras (24\%), em contrapartida, a uma notável redução dos investimentos com $\mathrm{P} \& \mathrm{D}(-33,5 \%)$. Tal movimento se relacionou com a aquisição de tecnologia (inovação) em processo a partir de fornecedores internacionais de $\mathrm{M} \& \mathrm{E}$, que viabiliza a modernização produtiva. Em 2008 a taxa de empresas inovadoras alcançou 51\%, sendo que $75 \%$ destas inovaram em processo, em essência, "Novos para as empresas", não para o mercado nacional.

Para os anos 2009-11, ocorreu a redução do número $(9,1 \%)$ e da taxa de empresas inovadoras no setor (51\% para $41 \%)$, apesar do aumento do número de empresas (em 12,2\%). Das inovadoras, mais de $70 \%$ inovaram em produto ou processo, e 42,5\% inovaram em ambos. Destacou-se a inovação "nova para o mercado nacional", com 39,4\% das inovações em produto e $11 \%$ em processo. Em relação a 2006-08, o dobro de empresas lançou produtos novos para o mercado nacional, o triplo em processo. Em complemento, aumentou o número e proporcional de empresas que inovaram em "Organização e marketing", assim como "Projetos incompletos ou abandonados".

Tabela 2 - Tipos de inovações promovidos pelas empresas da indústria de máquinas e equipamentos, número, proporcional de empresas e variação, Brasil, 2001-2014.

\begin{tabular}{|c|c|c|c|c|c|c|c|c|c|c|c|c|}
\hline \multirow[b]{2}{*}{ Descrição } & \multicolumn{10}{|c|}{ Período e Proporcional das Empresas } & \multicolumn{2}{|c|}{ VAR (\%) } \\
\hline & $\begin{array}{r}2001- \\
2003\end{array}$ & $(\%)$ & $\begin{array}{r}2003- \\
2005\end{array}$ & (\%) & $\begin{array}{r}2006- \\
2008\end{array}$ & $(\%)$ & $\begin{array}{r}2009- \\
2011\end{array}$ & $(\%)$ & $\begin{array}{r}2012- \\
2014\end{array}$ & $(\%)$ & $\begin{array}{r}2003- \\
2014\end{array}$ & $\begin{array}{r}2012- \\
2014\end{array}$ \\
\hline Total de empresas & 5411 & & 5799 & & 5551 & & 6228 & & 6588 & & 21,7 & 5,8 \\
\hline Empresas inovadoras* & 2354 & 44 & 2282 & 39 & 2831 & 51 & 2573 & 41 & 2657 & 40 & 12,9 & 3,3 \\
\hline Das Empresas inovadoras:** & & $100 \%$ & & $100 \%$ & & $100 \%$ & & $100 \%$ & & $100 \%$ & & \\
\hline Inovação de produto & 1674 & 71 & 1728 & 76 & 1781 & 63 & 1839 & 71 & 1650 & 62 & $-1,4$ & $-10,3$ \\
\hline Produto novo para a empresa & 1397 & 59 & 1239 & 54 & 1356 & 48 & 1075 & 42 & 1018 & 38 & $-27,1$ & $-5,3$ \\
\hline Produto novo no mercado nacion. & 346 & 15 & 524 & 23 & 560 & 20 & 1014 & 39 & 791 & 30 & 128,6 & $-22,0$ \\
\hline Inovação de processo & 1631 & 69 & 1350 & 59 & 2128 & 75 & 1827 & 71 & 2430 & 91 & 49,0 & 33,0 \\
\hline Processo novo para a empresa & 1566 & 67 & 1214 & 53 & 2066 & 73 & 1555 & 60 & 2262 & 85 & 44,4 & 45,5 \\
\hline Processo novo no mercado nacion. & 80 & 3,4 & 150 & 6,6 & 82 & 2,9 & 286 & 11,1 & 235 & 9 & 193,8 & $-17,8$ \\
\hline Inovação de produto e processo & 950 & 40 & 795 & 35 & 1078 & 38 & 1094 & 43 & 1423 & 54 & 49,8 & 30,1 \\
\hline Projetos inacabados e abandonad. & 186 & 7,9 & 224 & 10 & 111 & 3,9 & 396 & 15 & 155 & 6 & $-16,7$ & $-60,9$ \\
\hline Inovações organiz. e marketing & 1554 & 29 & 2105 & 36 & 1471 & 27 & 2113 & 82 & 2191 & 82 & 41,0 & 3,7 \\
\hline
\end{tabular}

Fonte: Elaboração própria, dados PINTEC (2003, 2005, 2008, 2011 e 2014).

* O proporcional das empresas nesta linha refere-se ao total de empresas do setor.

** O proporcional das empresas a partir desta linha refere-se ao total de empresas inovadoras do setor.

Entre 2009-11 e 2012-14 continuou a crescer o número de empresas do setor (em 5,8\%), as empresas inovadoras (em 3,3\%), mantendo a taxa de empresas inovadoras em 40\%. Destacou-se a inovação em processo, mais de $90 \%$ das empresas que inovaram, no qual $62 \%$ inovaram em produtos. Retomou-se a importância da $\mathrm{P} \& \mathrm{D}$ para implementação da inovação, nas empresas com estes departamentos. Isto possibilitou projetarem seus próprios produtos, em muitos casos, novos para o mercado nacional. Das 
inovações em produto, $44 \%$ trataram de "novos para o mercado nacional", proporcional superior ao do início do período $(20 \%, 30 \%, 29 \%$ e 49\%, nos anos de 2003, 2005, 2008 e 2011, respectivamente).

A partir da evolução do número, da taxa de empresas inovadoras, da novidade e espécie de inovação para a empresa e/ou mercado, e a análise por períodos nas páginas anteriores, observa-se que ocorreu a evolução nas capacidades de desenvolvimento tecnológico - principalmente em processos - das empresas inovadoras de $M \& E$ da indústria nacional. Esta tendência, para o caso das inovações em produto, foi gradual ao longo da década. Para o caso das inovações em processo apenas a partir de 2009 se destacou o movimento de inovação para o mercado nacional. Para o fim do período analisado, 2011 a 2014, das empresas inovadoras $62 \%$ inovaram em produto, dentre os quais $48 \%$ para o mercado nacional, enquanto 91\% inovaram em processo, sendo $10 \%$ para o mercado nacional. Apesar do maior proporcional de empresas inovando em processo ao longo do período, foi a inovação dos produtos que se destacou como "Novos para o mercado nacional".

A redução dos níveis de investimento com P\&D interno observado ao longo dos anos 2000 foi um movimento observado em diversos setores da indústria de transformação brasileira, mas se destacou em M\&E: o índice caiu de 1,2\% para 0,5\%, entre 2000 e 2008. Para a presente década este percentual alcançou 0,73\% no ano de 2011 (nível similar ao da indústria de transformação), e 0,8\% em 2014. A retomada do investimento veio acompanhada do reestabelecimento da importância da P\&D como atividade inovativa para o desenvolvimento tecnológico das empresas no setor, para as empresas que investem neste departamento/atividade (visível na Tabela 4). Na indústria de transformação, a retomada foi mais sutil (níveis de 0,7\% em 2000, 0,6\% nos anos de 2003, 2005 e 2008, retornando para 0,7\% entre 2011 e 2014).

No plano dos dispêndios com atividades para a inovação, o setor seguiu intensivo em gastos com "outras atividades inovadoras", principalmente "aquisição de M\&E", em detrimento ao investimento com P\&D. Ao longo do período analisado (2001 - 2014), em média, os dispêndios com atividades para inovação somaram $3,1 \%$ da receita líquida de vendas, dentre os quais $0,7 \%$ foi investido em $P \& D, 1,6 \%$ na aquisição de novas M\&E, e 0,8\% em outras atividades como aquisição de P\&D e/ou outros conhecimentos externos, aquisição de softwares, treinamento, introdução das inovações tecnológicas no mercado, projetos industriais e outras preparações técnicas. Nestes termos, a aquisição de M\&E foi considerada a atividade mais importante e dispendiosa para as empresas atualizarem suas capacidades de desenvolvimento tecnológico (informações visíveis nas Tabelas 3 e 4).

Tabela 3 - Dispêndios realizados nas atividades inovativas com relação a receita líquida de vendas das empresas produtoras de M\&E no Brasil, proporcional (\%), 2001 a 2014.

\begin{tabular}{|c|c|c|c|c|c|c|c|}
\hline Descrição \Ano & 2000 & 2003 & 2005 & 2008 & 2011 & 2014 & Média \\
\hline \multicolumn{8}{|c|}{ Gastos com atividades inovativas/ Receita líquida - Percentual (\%) } \\
\hline Indústria de transformação & 3,9 & 2,5 & 2,8 & 2,6 & 2,5 & 2,2 & 2,8 \\
\hline Indústria de M\&E & 4,1 & 3,3 & 4,1 & 3 & 2,1 & 2,2 & 3,1 \\
\hline \multicolumn{8}{|c|}{ P\&D/Receita Líquida - Percentual (\%) } \\
\hline Indústria de transformação & 0,65 & 0,55 & 0,58 & 0,64 & 0,72 & 0,68 & 0,6 \\
\hline Indústria de M\&E & 1,15 & 0,71 & 0,55 & 0,46 & 0,73 & 0,8 & 0,7 \\
\hline \multicolumn{8}{|c|}{ Outros gastos atividades inovativas/ Receita Líquida - Percentual (\%) } \\
\hline Indústria de transformação & 3,2 & 1,9 & 2,2 & 2 & 1,74 & 1,48 & 2,1 \\
\hline Indústria de M\&E & 3 & 2,5 & 3,6 & 2,6 & 1,38 & 1,38 & 2,4 \\
\hline \multicolumn{8}{|c|}{ Aquisição M\&E/Receita Líquida - Percentual (\%) } \\
\hline Indústria de transformação & 2 & 1,2 & 1,3 & 1,3 & 1,16 & 0,86 & 1,3 \\
\hline Indústria de M\&E & 2 & 1,9 & 1,8 & 2 & 0,91 & 0,87 & 1,6 \\
\hline
\end{tabular}

Fonte: Elaboração própria, dados PINTEC (2003, 2005, 2008 e 2011).

Ao longo do período analisado, ocorreu a redução dos gastos com as atividades inovativas na indústria de transformação e de M\&E, tanto para a aquisição de M\&E, P\&D ou outras atividades (Tabela 3). Em contrapartida, aumentou as capacidades de inovação das empresas do setor, com base na taxa de inovação de empresas, novos produtos para o mercado nacional e processos para as empresas (como 
apontado anteriormente). Isto significa que as empresas produtoras de M\&E da economia nacional se basearam em outras atividades inovativas menos dispendiosas que P\&D e aquisição de M\&E para fortalecerem suas capacidades de desenvolvimento tecnológico (inovações em processo ou produto). A utilização de outras atividades para a inovação e o aumento da absorção de conhecimento tecnológico por via de outras fontes ou agentes externos podem ser consideradas alternativas para os elevados gastos com atividades voltadas para inovação.

As formas de geração de capacidades para o desenvolvimento tecnológico consolidadas mais importantes, conforme a Tabela 4, foram: $\left(1^{\circ}\right)$ a "Aquisição de máquinas e equipamentos", principalmente para o início da década e entre 2006-08; $\left(2^{\circ}\right)$ "Treinamento", ao longo de toda a década, tornando-se quase tão importante como aquisição de M\&E; em seguida, ocorreu a ( $\left.3^{\circ}\right)$ "Aquisição de software"; enquanto as “Atividades internas de P\&D” seguem na (4") posição como atividade de mais alta importância para a capacitação tecnológica na indústria de M\&E.

Tabela 4 - Grau de importância* (alta, média e baixa) das atividades inovadoras para as empresas da indústria de máquinas e equipamentos que inovaram no Brasil, em números, variação e proporcional de empresas, 2001-2014.

\begin{tabular}{|c|c|c|c|c|c|c|c|c|c|c|c|c|c|}
\hline \multirow{2}{*}{\multicolumn{2}{|c|}{ Descrição }} & \multicolumn{10}{|c|}{ Período } & \multicolumn{2}{|c|}{ VAR (\%) } \\
\hline & & $\begin{array}{r}2001- \\
2003\end{array}$ & $\%$ & $\begin{array}{r}2003- \\
2005\end{array}$ & $\%$ & $\begin{array}{r}2006- \\
2008\end{array}$ & $\%$ & $\begin{array}{r}2009- \\
2011\end{array}$ & $\%$ & $\begin{array}{r}2012- \\
2014\end{array}$ & $\%$ & $\begin{array}{r}2003- \\
2014\end{array}$ & $\begin{array}{r}2011- \\
2014\end{array}$ \\
\hline \multicolumn{2}{|c|}{ Empresas inovadoras da indústria } & 2.354 & & 2.282 & & 2.831 & & 2573 & & 2657 & & 12,9 & 3,3 \\
\hline \multirow{3}{*}{ Atividades Internas de P\&D } & Alta & 697 & 30 & 664 & 29 & 343 & 12 & 639 & 25 & 519 & 20 & $-25,6$ & $-18,8$ \\
\hline & Média & 121 & 5 & 212 & 9 & 143 & 5 & 618 & 24 & 194 & 7 & 60,0 & $-68,7$ \\
\hline & Baixa & 1.537 & 65 & 1.406 & 62 & 2.345 & 83 & 1316 & 51 & 1945 & 73 & 26,5 & 47,8 \\
\hline \multirow{3}{*}{ Aquisição externa de P\&D } & Alta & 45 & 2 & 170 & 7 & 142 & 5 & 121 & 5 & 64 & 2 & 43,0 & $-46,8$ \\
\hline & Média & 25 & 1 & 24 & 1 & 29 & 1 & 46 & 2 & 64 & 2 & 157,3 & 39,8 \\
\hline & Baixa & 2.284 & 97 & 2.088 & 91 & 2.659 & 94 & 2406 & 94 & 2529 & 95 & 10,7 & 5,1 \\
\hline \multirow{3}{*}{$\begin{array}{l}\text { Aquisição de outros } \\
\text { conhecimentos externos }\end{array}$} & Alta & 203 & 9 & 258 & 11 & 201 & 7 & 165 & 6 & 247 & 9 & 21,5 & 49,5 \\
\hline & Média & 63 & 3 & 100 & 4 & 126 & 4 & 177 & 7 & 151 & 6 & 139,0 & $-14,9$ \\
\hline & Baixa & 2.088 & 89 & 1.924 & 84 & 2.504 & 88 & 2231 & 87 & 2260 & 85 & 8,2 & 1,3 \\
\hline \multirow{3}{*}{$\begin{array}{l}\text { Aquisição de Máquinas e } \\
\text { equipamentos }\end{array}$} & Alta & 1.515 & 64 & 1.052 & 46 & 1.634 & 58 & 995 & 39 & 1208 & 45 & $-20,2$ & 21,4 \\
\hline & Média & 297 & 13 & 299 & 13 & 491 & 17 & 418 & 16 & 398 & 15 & 33,9 & $-4,9$ \\
\hline & Baixa & 542 & 23 & 931 & 41 & 706 & 25 & 1160 & 45 & 1051 & 40 & 94,0 & $-9,4$ \\
\hline \multirow{3}{*}{ Treinamento } & Alta & 1.069 & 45 & 1.033 & 45 & 1.011 & 36 & 937 & 36 & 1099 & 41 & 2,8 & 17,3 \\
\hline & Média & 438 & 19 & 288 & 13 & 692 & 24 & 565 & 22 & 668 & 25 & 52,4 & 18,2 \\
\hline & Baixa & 848 & 36 & 960 & 42 & 1.128 & 40 & 1071 & 42 & 890 & 34 & 5,0 & $-16,9$ \\
\hline \multirow{3}{*}{$\begin{array}{l}\text { Introdução das inovações } \\
\text { Tecnológicas no mercado }\end{array}$} & Alta & 354 & 15 & 600 & 26 & 402 & 14 & 447 & 17 & 448 & 17 & 26,6 & 0,2 \\
\hline & Média & 235 & 10 & 236 & 10 & 397 & 14 & 393 & 15 & 556 & 21 & 136,6 & 41,5 \\
\hline & Baixa & 1.765 & 75 & 1.446 & 63 & 2.032 & 72 & 1732 & 67 & 1653 & 62 & $-6,3$ & $-4,5$ \\
\hline \multirow{3}{*}{$\begin{array}{l}\text { Projeto industrial e outras } \\
\text { preparações técnicas }\end{array}$} & Alta & 832 & 35 & 720 & 32 & 879 & 31 & 541 & 21 & 766 & 29 & $-7,9$ & 41,6 \\
\hline & Média & 430 & 18 & 383 & 17 & 356 & 13 & 288 & 11 & 384 & 14 & $-10,8$ & 33,2 \\
\hline & Baixa & 1.092 & 46 & 1.178 & 52 & 1.596 & 56 & 1743 & 68 & 1507 & 57 & 38,0 & $-13,5$ \\
\hline \multirow{3}{*}{ Aquisição de Softwares } & Alta & - & & 425 & 19 & 881 & 31 & 863 & 34 & 790 & 30 & - & $-8,5$ \\
\hline & Média & - & & 127 & 6 & 432 & 15 & 209 & 8 & 275 & 10 & - & 31,4 \\
\hline & Baixa & - & & 1.730 & 76 & 1.518 & 54 & 1501 & 58 & 1593 & 60 & - & 6,1 \\
\hline
\end{tabular}

Fonte: Elaboração própria, dados PINTEC (2003, 2005, 2008 e 2011).

* Os níveis de importância que se encontram na segunda coluna da Tabela são: alta, média e baixa importância. Quando solicitadas as empresas deveriam escolher um dos três níveis para cada atividade. Nas terceira e quata colunas, respectivamente, se encontram (i) a quantidade de empresas que consideram aquele nível de importância da atividade, e (ii) o proporciona de empresas, com relação ao total de empresas inovadoras do setor. 
A "Aquisição de máquinas e equipamentos" para a capacitação tecnológica das empresas foi considerada como principal característica o repasse tecnológico dos fornecedores (tecnologia externa), principalmente em processo, que viabiliza a atualização produtiva do setor. A "Aquisição de software" seguiu com características similares, gerando capacidades em projetos, alterações na estrutura de operação das máquinas, e, eficiência produtiva. Neste quadro, deve-se considerar que as atividades de P\&D e os investimentos com projetos se relacionam com a capacidade de desenvolvimento de novos produtos, ou adaptação de novas tecnologias. O "Treinamento" que capacita os recursos humanos da firma para o processo de inovação, embora seja a $2^{\mathrm{a}}$ atividade mais importante, contou com menos de $2 \%$ dos investimentos.

A aquisição de M\&E e de software, como meios de capacitação tecnológica, se relaciona com o aprendizado das empresas no ato de fazer (learning by doing) e usar (learning by using), que ocorrem no ambiente interno das empresas. A aquisição de um novo maquinário ou software traz a necessidade de absorver novos conhecimentos, técnicas e capacidades, que ativam na empresa o processo de aprender pelo ato de "fazer", construir, ou desenvolver, seus produtos a partir de um novo processo com novos softwares ou maquinários em suas linhas de produção. Ocorre o desenvolvimento de habilidades dentro das atividades produtivas, e meio ao estágio de produção industrial. Uma série de modificações e inovações incrementais são susceptíveis de ocorrerem, na medida que a empresa aprende melhor sobre o processo e o desempenho dos produtos.

Após o processo de instalação do maquinário adquirido, absorção ou desenvolvimento de novas habilidades e técnicas sobre como fazer/produzir os produtos, as novas M\&E e softwares são utilizados exaustivamente na produção de outras M\&E (no caso da indústria de $\mathrm{BC}$ ), ocorrendo o processo de aprendizado pelo ato de usar (learning by using). Para a empresa que utiliza esta nova estrutura, o reconhecimento de novas práticas, materiais, combinações, defeitos e possibilidades de uso gera conhecimento e capacidades permitem melhorias incrementais no desempenho dos produtos/processos.

Em plano teórico Rosemberg (2006) já destacava a importância dos processos de aprendizado by doing e by using para a produção de Bens de Capital, uma vez que se trata de bens duráveis, e suas características não podem ser entendidas antes de uma prolongada experiência de uso e produção deste equipamento. Os resultados empíricos seguem na direção desta perspectiva teórica.

Tabela 5 - Principal responsável pelas inovações, em produto ou processo, das empresas inovadoras da indústria de máquinas e equipamentos do Brasil, em números, variação e proporcional de empresas, 2001-2014.

\begin{tabular}{|c|c|c|c|c|c|c|c|c|c|c|c|c|}
\hline \multirow[b]{2}{*}{ Descrição } & \multicolumn{10}{|c|}{ Período } & \multicolumn{2}{|c|}{ VAR (\%) } \\
\hline & $\begin{array}{r}2001- \\
2003\end{array}$ & $\%$ & $\begin{array}{r}2003- \\
2005\end{array}$ & $\%$ & $\begin{array}{r}2006- \\
2008\end{array}$ & $\%$ & $\begin{array}{r}2009- \\
2011\end{array}$ & $\%$ & $\begin{array}{r}2012- \\
2014\end{array}$ & $\%$ & $\begin{array}{r}2003- \\
2014\end{array}$ & $\begin{array}{r}2011- \\
2014\end{array}$ \\
\hline Em produto: & 1.674 & & 1.728 & & 1.781 & & 1839 & & 1650 & & -1 & $-10,3$ \\
\hline A empresa & 1.512 & 90 & 1.539 & 89 & 1.495 & 84 & 1689 & 91,8 & 1324 & 80,3 & -12 & $-21,6$ \\
\hline Outra empresa do grupo & 45 & 3 & 37 & 2 & 35 & 2 & 36 & 2 & 101 & 6,1 & 125 & 182 \\
\hline Cooperação com empresas/instit. & 24 & 1,4 & 88 & 5 & 178 & 10 & 69 & 3,8 & 175 & 10,6 & 629 & 154 \\
\hline Outras empresas ou instituições & 93 & 5,6 & 63 & 3,6 & 72 & 4 & 45 & 2,4 & 49 & 3,0 & -47 & 9,7 \\
\hline Em processo: & 1.631 & & 1.350 & & 2.128 & & 1827 & & 2430 & & 49 & 33 \\
\hline A empresa & 78 & 4,8 & 263 & 20 & 282 & 13 & 573 & 31 & 918 & 38 & 1078 & 60 \\
\hline Outra empresa do grupo & 12 & 0,7 & 21 & 1,6 & 19 & 1 & 32 & 2 & 67 & 3 & 455 & 108 \\
\hline Cooperação com empresas/instit. & 18 & 1,1 & 45 & 3 & 48 & 2 & 72 & 4 & 195 & 8 & 981 & 170 \\
\hline Outras empresas ou instituições & 1.523 & 93 & 1.021 & 76 & 1.780 & 84 & 1150 & 63 & 1251 & 51 & -18 & 8,8 \\
\hline
\end{tabular}

Fonte: Elaboração própria, dados PINTEC (2003, 2005, 2008 e 2011).

* Proporcional de empresas com relação ao total de empresas que inovaram em (i) produto, ou (ii) processo.

O usuário retorna para o produtor informações pertinentes que são utilizadas para melhorar o produto, a partir do mecanismo learning by using. A partir deste último desenvolve-se o aprendizado 
learning by doing no produtor. Em meio a esta interação ocorre o learning by interacting, a partir da combinação do aprendizado interno (dentro da própria fábrica) com externo (aqueles que ocorrem com consumidores e fornecedores). A análise das relações com estes agentes possibilita mensurar a intensidade do processo de aprendizado.

O treinamento, por sua vez, possibilita melhorar os processos de aprendizado e podem ser direcionados, assim como os resultados esperados. Sendo assim, não se encontra atrelado a um processo de aprendizado específico, pode ser utilizado para melhorar habilidades, capacidades e meios de aprendizado específico ou geral.

O substancial crescimento das inovações "Novas para o mercado" e o posicionamento ativo de um seleto grupo de empresas no que tange o investimento em P\&D se relacionam com o aprendizado por meio da busca/pesquisa (learning by searching). Este processo também ocorre em ambiente interno através da formalização de atividades ligadas ao desenvolvimento tecnológico, que faz gerar novos conhecimentos. Apesar da P\&D exemplificar o caso, não ocorre apenas desta forma. A busca por novos conhecimentos e técnicas, o monitoramento, e as atividades para o desenvolvimento tecnológico que gera novos conhecimentos e amplia as capacidades para inovar pode ser encontrado nas rotinas e diferentes departamentos da firma. Este esforço, direcionado para o desenvolvimento tecnológico, possibilita as empresas traçarem suas próprias trajetórias, elaborando seus próprios produtos ou processos para produzilos.

No caso das inovações em produto, a própria empresa foi a principal responsável pela inovação (92\% das inovações em 2009-11, 80\% em 2012-2014). Por outro lado, ocorreu a evolução do proporcional e número de inovações em produto "Novos para o mercado nacional", que alcançou 52\% e 56\% das inovações em produto no período de 2009-11 e 2012-12. Além de serem as principais responsáveis, destacase justamente que empresas do setor tem apresentado capacidades de inovação para o mercado.

Considerando as inovações em processos, confirmou-se o repasse tecnológico através dos fornecedores (outras empresas e instituições), mesmo que tenha ocorrido a redução da participação deste responsável para inovações em processo. Em 2001-03, 93\% das inovações em processo deveu-se ao repasse externo. Em 2012-14 este proporcional baixou para 51\%. Ganhou importância a própria empresa como responsável pelas próprias inovações em processo, alcançando 31\% das empresas que inovaram neste quesito em 2011, 38\% em 2014.

Sendo assim, no plano das fontes de informações tecnológicas externas (Tabela 6) que as empresas fazem uso para atualizarem conhecimento e capacidades, por ordem de importância, tem-se: $\left(1^{\circ}\right)$ "Clientes/consumidores", $\left(2^{\circ}\right)$ "Redes de informação informatizadas", $\left(3^{\circ}\right)$ "Fornecedores" e $\left(4^{\circ}\right)$ "Feiras e exposições", ganhando importância outras fontes de informação como: "concorrentes, consultoria, centro de capacitação profissional e instituições de testes, ensaios e certificações". Perdeu importância relativa "Feiras e exposições, conferências, encontros e publicações". Apesar de uma estrutura estável das fontes de informação para inovação das empresas ao longo do período analisado, de forma sutil, ocorreu uma diversificação destas fontes.

O relacionamento com "Clientes/consumidores" e "Fornecedores" são fontes de informação que se relacionam diretamente com o aprendizado por meio da interação (learning by interacting). Foi destacado que o usuário retorna para o produtor informações pertinentes sobre um produto que serão utilizadas para sua melhora, desenvolvendo o aprendizado learning by doing no produtor, a partir do learning by using do usuário. Em meio a esta interação ocorre o learning by interacting, a partir da combinação do aprendizado interno (dentro da própria fábrica) com externo (aqueles que ocorrem com consumidores e fornecedores). Os dados confirmam que este processo de aprendizado foi fundamental para a capacitação tecnológica das firmas no setor. Tais mecanismos de ganharam relevância em detrimento do aprendizado por meio de busca (learning by searching), apesar do retorno da importância deste aprendizado nos últimos anos analisados.

A cooperação pode potencializar o progresso tecnológico, reduzindo/diluindo custos com pesquisas e facilitando transferência de conhecimento/técnicas. As parcerias ocorrem nos planos produtivo, tecnológico, mercadológico ou organizacional. Quando as empresas buscam o desenvolvimento tecnológico, a cooperação toma contornos de transformação industrial, potencializando o desenvolvimento de processos e de novos produtos nas empresas envolvidas. Considerando os dados coletados, os objetivos 
mais comuns para a cooperação foram (Tabela 7): treinamento, investimentos em P\&D, testes, ensaios, troca de informações e desenvolvimento tecnológico conjunto.

Tabela 6 - Importância das fontes de informação para as empresas da indústria de máquinas e equipamentos que implementaram inovações no Brasil, em números, variação e proporcional de empresas, 2001 - 2014.

\begin{tabular}{|c|c|c|c|c|c|c|c|c|c|c|c|c|c|}
\hline \multirow{2}{*}{\multicolumn{2}{|c|}{ Descrição/Importância }} & \multirow{3}{*}{$\begin{array}{r}\mathbf{2 0 0 1 -} \\
\mathbf{2 0 0 3} \\
2.354 \\
\end{array}$} & \multicolumn{9}{|c|}{ Período e proporcional de empresas } & \multicolumn{2}{|c|}{ VAR (\%) } \\
\hline & & & o/ & 2003- & o/ & 2006- & o/ & 2009- & o/ & 2012- & \multirow{2}{*}{$\%$} & \multirow{2}{*}{$\begin{array}{r}\mathbf{2 0 0 3 -} \\
\mathbf{2 0 1 4} \\
13 \\
\end{array}$} & \multirow{2}{*}{$\begin{array}{r}2011- \\
2014 \\
3 \\
\end{array}$} \\
\hline Total de empresas que in & ovaram & & & 2.282 & & 2.831 & & 2573 & & 2657 & & & \\
\hline Fontes Internas & - & - & - & - & - & - & - & - & - & & - & - & \\
\hline \multirow{3}{*}{ Departamento de P\&D } & Alta & 289 & 12 & 296 & 13 & 341 & 12 & 719 & 28 & 520 & 20 & 80 & -28 \\
\hline & Média & 49 & 2 & 84 & 4 & 113 & 4 & 215 & 8 & 90 & 3 & 83 & -58 \\
\hline & Baixa & 487 & 21 & 512 & 22 & 61 & 2 & 520 & 20 & 245 & 9 & -50 & -53 \\
\hline \multirow{3}{*}{ Outras áreas } & Alta & 1.348 & 57 & 1056 & 46 & 1368 & 48 & 688 & 27 & 875 & 33 & -35 & 27 \\
\hline & Média & 394 & 17 & 492 & 22 & 752 & 27 & 809 & 31 & 732 & 28 & 86 & -10 \\
\hline & Baixa & 612 & 26 & 734 & 32 & 711 & 25 & 1076 & 42 & 1050 & 40 & 72 & -2 \\
\hline \multicolumn{2}{|l|}{ Fontes Externas } & & - & & - & & - & & - & & - & - & \\
\hline \multirow{3}{*}{$\begin{array}{l}\text { Outra empresa do } \\
\text { Grupo }\end{array}$} & Alta & 149 & 6 & 99 & 4 & 346 & 12 & 103 & 4 & 194 & 7 & 30 & 88 \\
\hline & Média & 42 & 2 & 36 & 2 & 47 & 2 & 44 & 2 & 116 & 4 & 176 & 164 \\
\hline & Baixa & 116 & 5 & 153 & 7 & 115 & 4 & 200 & 8 & 147 & 6 & 27 & -26 \\
\hline \multirow{3}{*}{ Fornecedores } & Alta & 656 & 28 & 855 & 38 & 938 & 33 & 734 & 29 & 712 & 27 & 9 & -3 \\
\hline & Média & 578 & 25 & 507 & 22 & 1021 & 36 & 693 & 27 & 993 & 37 & 72 & 43 \\
\hline & Baixa & 1.120 & 48 & 920 & 40 & 871 & 31 & 1146 & 45 & 952 & 36 & -15 & -17 \\
\hline \multirow{3}{*}{ Clientes/consumidores } & Alta & 1051 & 45 & 1313 & 58 & 1291 & 46 & 1138 & 44 & 1306 & 49 & 24 & 15 \\
\hline & Média & 521 & 22 & 490 & 22 & 855 & 30 & 791 & 31 & 920 & 35 & 77 & 16 \\
\hline & Baixa & 782 & 33 & 479 & 21 & 684 & 24 & 643 & 25 & 431 & 16 & -45 & -33 \\
\hline \multirow{3}{*}{ Concorrentes } & Alta & 434 & 18 & 451 & 20 & 502 & 18 & 464 & 18 & 472 & 18 & 9 & 2 \\
\hline & Média & 421 & 18 & 468 & 21 & 630 & 22 & 586 & 23 & 815 & 31 & 94 & 39 \\
\hline & Baixa & 1.500 & 64 & 1363 & 60 & 1698 & 60 & 1522 & 59 & 1370 & 52 & -9 & -10 \\
\hline \multirow{3}{*}{ Consultoria } & Alta & 116 & 5 & 265 & 12 & 267 & 9 & 156 & 6 & 184 & 7 & 59 & 18 \\
\hline & Média & 136 & 6 & 137 & 6 & 490 & 17 & 385 & 15 & 247 & 9 & 81 & -36 \\
\hline & Baixa & 2102 & 89 & 1880 & 82 & 2074 & 73 & 2031 & 79 & 2226 & 84 & 6 & 10 \\
\hline \multirow{3}{*}{$\begin{array}{l}\text { Universidades e } \\
\text { Centros de Pesquisa }\end{array}$} & Alta & 136 & 6 & 218 & 10 & 163 & 6 & 199 & 8 & 91 & 3 & -33 & -54 \\
\hline & Média & 82 & 4 & 122 & 5 & 325 & 12 & 254 & 10 & 212 & 8 & 159 & -17 \\
\hline & Baixa & 2136 & 91 & 1941 & 85 & 2343 & 83 & 2119 & 82 & 2354 & 89 & 10 & 11 \\
\hline \multirow{3}{*}{$\begin{array}{l}\text { Institutos de pesquisa } \\
\text { ou centros tecnológicos }\end{array}$} & Alta & - & & - & & 240 & 9 & 188 & 7 & 164 & 6 & - & -13 \\
\hline & Média & - & & - & & 172 & 6 & 193 & 8 & 269 & 10 & - & 39 \\
\hline & Baixa & - & & - & & 2419 & 85 & 2192 & 85 & 2224 & 84 & - & 1 \\
\hline \multirow{3}{*}{$\begin{array}{l}\text { Centros de Capacitação } \\
\text { Profissional e Ass. } \\
\text { Técnica }\end{array}$} & Alta & 115 & 5 & 236 & 10 & 359 & 13 & 170 & 7 & 253 & 10 & 120 & 49 \\
\hline & Média & 248 & 11 & 225 & 10 & 336 & 12 & 444 & 17 & 383 & 14 & 55 & -14 \\
\hline & Baixa & 1.991 & 85 & 1821 & 80 & 2136 & 76 & 1959 & 76 & 2021 & 76 & 2 & 3 \\
\hline \multirow{3}{*}{$\begin{array}{l}\text { Instituições de testes, } \\
\text { ensaios e certificações }\end{array}$} & Alta & 216 & 9 & 239 & 11 & 243 & 9 & 349 & 14 & 240 & 9 & 11 & -31 \\
\hline & Média & 288 & 12 & 296 & 13 & 355 & 13 & 395 & 15 & 436 & 16 & 51 & 10 \\
\hline & Baixa & 1851 & 79 & 1746 & 77 & 2232 & 79 & 1828 & 71 & 1981 & 75 & 7 & 8 \\
\hline & Alta & 277 & 12 & 401 & 18 & 490 & 17 & 214 & 8 & 260 & 10 & -6 & 22 \\
\hline Conferencias, encontros & Média & 592 & 25 & 431 & 19 & 439 & 16 & 455 & 18 & 479 & 18 & -19 & 5 \\
\hline & Baixa & 1.486 & 63 & 1450 & 64 & 1901 & 67 & 1904 & 74 & 1918 & 72 & 29 & 1 \\
\hline & Alta & 995 & 42 & 871 & 38 & 1134 & 40 & 569 & 22 & 975 & 37 & -2 & 71 \\
\hline Feira e Exposições & Média & 533 & 23 & 542 & 24 & 656 & 23 & 492 & 19 & 856 & 32 & 61 & 74 \\
\hline & Baixa & 826 & 35 & 869 & 38 & 1040 & 37 & 1512 & 59 & 827 & 31 & 0 & -45 \\
\hline & Alta & 816 & 35 & 959 & 42 & 1540 & 54 & 976 & 38 & 1604 & 60 & 97 & 64 \\
\hline Redes de informaçao & Média & 486 & 21 & 590 & 26 & 629 & 22 & 546 & 21 & 539 & 20 & 11 & -1 \\
\hline & Baixa & 1.053 & 45 & 733 & 32 & 662 & 23 & 1051 & 41 & 515 & 19 & -51 & -51 \\
\hline
\end{tabular}

Fonte: Elaboração própria, dados PINTEC (2003, 2005, 2008, 2011 e 2014). 
As parceiras com universidades e centros de pesquisa viabilizam tanto o desenvolvimento como ensaios de novos produtos, além de muitas vezes trazerem inovações em processos para as empresas. A parceria/cooperação tecnológica com concorrentes, além do repasse de informações tecnológicas, também pode reduzir custos com P\&D ou com as atividades inovativas, ou mesmo desenvolver produtos e processos em determinada trajetória tecnológica individual e diferenciada, beneficiando ambas as empresas.

Considerando tais aspectos, das empresas inovadoras, conforme a Tabela 7, 17\% apresentaram parceria ou cooperação entre 2012-2014, 27\% no período de 2009-2011. Percentual ainda é baixo, mas o crescimento foi substancial. Entre 2001-03, 4,5\% das empresas inovadoras estabeleceram cooperação, 9\% entre 2003-05 e 14\% entre 2006-08. Subiu de 393 para 687 o número de empresas que estabeleceram cooperação entre 2008 e 2011 ( $27 \%$ das empresas inovadoras), reduzindo para 439 empresas entre 2012 e 2014 (17\% das empresas inovadoras). Foi crescente não apenas o número de empresas, mas a importância para estas empresas, a colaboração para potencializar suas capacidades de desenvolvimento tecnológico.

As características mais relevantes apontadas indicam que empresas ativas buscam por desenvolvimento de tecnologia, geram suas oportunidades econômicas e constroem trajetórias tecnológicas de produtos e processos, a partir de seus esforços de busca, absorção de conhecimento e desenvolvimento de capacidades tecnológicas. Gera-se, em algumas empresas, tecnologia nova até mesmo para o mercado. As outras empresas se destacam como conservadoras ou imitadoras, cuja busca tecnológica se baseiam na absorção e adaptação de tecnologia existente.

Tabela 7 - Grau de importância da parceria para as empresas da indústria de máquinas e equipamentos que mantêm cooperação com outras empresas ou instituições no Brasil, em números, variação e proporcional de empresas, 2001 - 2014.

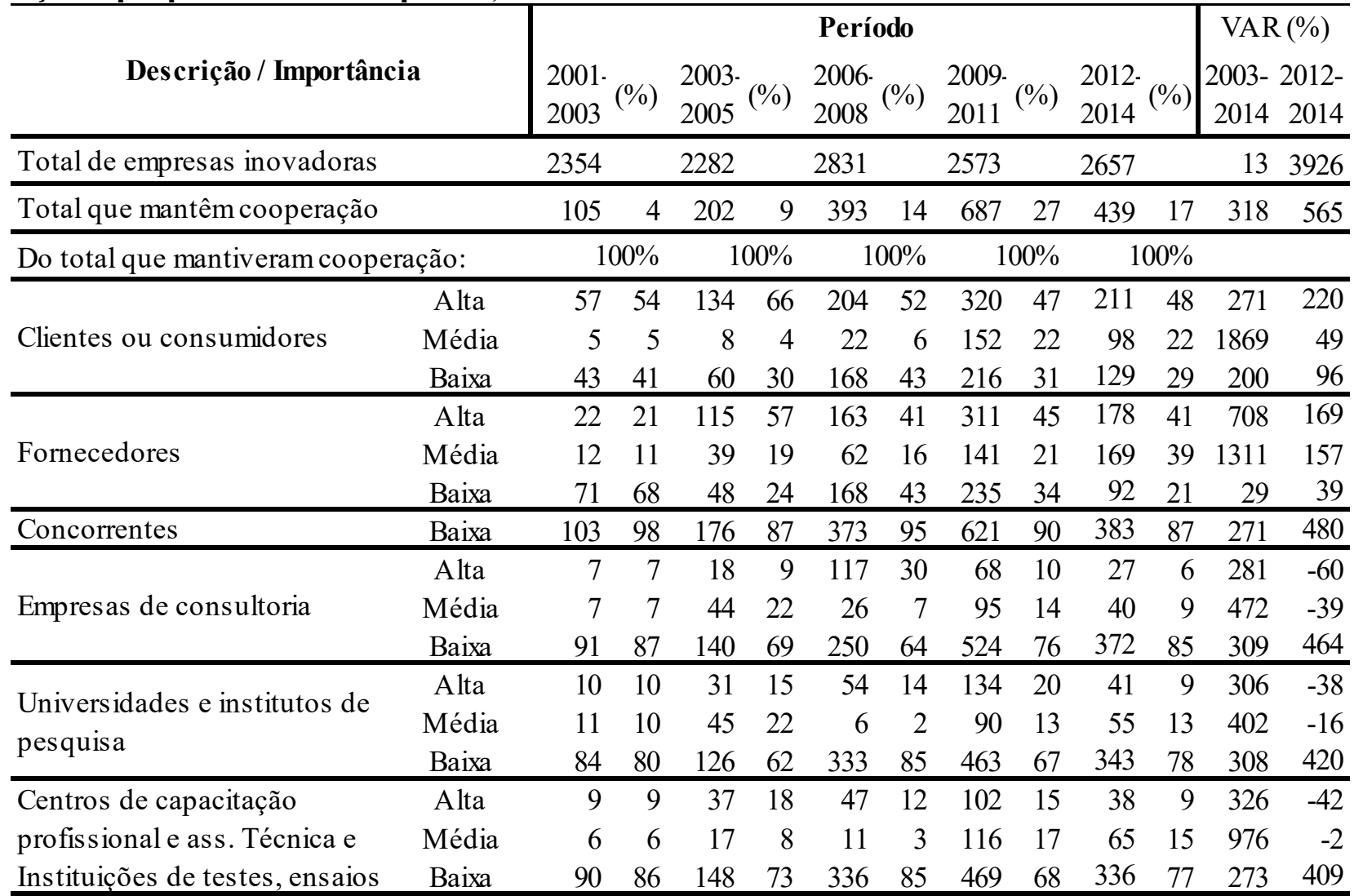

Fonte: Elaboração própria, dados PINTEC (2003, 2005, 2008, 2011 e 2014).

* Proporcional de empresas com relação ao total de empresas que mantiveram cooperação.

A evolução da "Cooperação para o desenvolvimento das inovações" das empresas no setor, por sua vez, pode ser analisada a partir da Tabela 7. Os "Clientes/consumidores" seguido pelos "Fornecedores" 
foram os principais parceiros. Universidades e institutos de pesquisa, junto com os Centros de capacitação, assistência técnica e as instituições de testes, ensaios e certificações, seguiram como outros importantes parceiros, apesar de serem importantes para uma pequena proporção de empresas. Consultoria foi importante entre 2006-08, enquanto os clientes e fornecedores atingiram sua maior importância entre 200305. As parcerias com universidades e institutos de pesquisa foram as que mais exibiram o objetivo de "P\&D e ensaios para testes de produtos".

\section{CONCLUSÕES}

No plano das características das inovações, apesar da redução da taxa de empresas inovadoras (proporção de empresas que inovaram em relação ao total de empresas) no segmento de M\&E nos últimos anos analisados, os resultados demonstraram o aumento da importância da própria empresa como o principal responsável pelas inovações para si própria, e também para o mercado. As empresas não apenas copiaram e incrementaram inovações em produto já existentes ao seu portfólio, mas lançaram "Novos produtos no mercado nacional", e em menor escala, "Novos processos no mercado nacional". Este desempenho inovativo de lançar novos produtos e processos demonstram aumento da capacidade de as empresas desenvolverem sua própria tecnologia.

Teoricamente, as capacidades dinâmicas dizem respeito a capacidade de uma empresa ou grupo de empresas (até mesmo um setor produtivo) ir além da inovação, e reconstruir seus meios e capacidade de se adaptar e inovar. $\mathrm{O}$ desempenho (resultados) em inovações de um setor/empresa está ligado às capacidades de inovação, uma capacidade substancial, não dinâmica. A dificuldade em mensurar a capacidade dinâmica nos levou a analisar os processos de aprendizado e seus resultados, que apesar de não explicitar as capacidades complexas que geram os resultados, demonstraram como ocorreu o processo de absorção de um determinado conhecimento de uma fonte ou atividades que puderam transformar o conhecimento tecnológico, gerando os resultados observados e o processo de aprendizado envolvido. Para isto, além das características (resultados) das inovações, foi fundamental entender quais as principais atividades/práticas que potencializaram o desenvolvimento das inovações, quais os resultados e utilidades destas atividades para as empresas, as fontes de informação interna e externa utilizadas, assim como os resultados possíveis de serem alcançados, vinculados aos seus processos de aprendizagem específicos.

No plano das atividades que potencializaram o desenvolvimento das inovações, os resultados apontaram que as principais atividades foram: $\left(1^{\circ}\right)$ a "Aquisição de M\&E"; $\left(2^{\circ}\right)$ "Treinamento"; $\left(3^{\circ}\right)$ "Aquisição de software"; e, $\left(4^{\mathrm{a}}\right)$ as "Atividades internas de P\&D". A aquisição de M\&E se posicionou como principal fonte tecnológica para as empresas no setor (principalmente para os processos produtivos), e tem como característica o repasse tecnológico dos fornecedores (tecnologia exógena). O "Treinamento", por sua vez, possibilitou a renovação de conhecimento e práticas internas às empresas, potencializando as capacidades não apenas para a inovação. A "Aquisição de software" seguiu com características similares a de aquisição de M\&E, entretanto, gerou capacidade no desenvolvimento de projetos, alterações na estrutura de operação das máquinas e eficiência produtiva. As “Atividades internas de P\&D” e desenvolvimento de projetos demonstraram ser importantes, assim como alvo de investimentos, apenas para um seleto grupo de empresas do setor, e se relacionou intimamente com o desenvolvimento interno de projetos dos novos produtos e novas tecnologias para produzi-los.

Dentre as práticas, confirmou-se que o relacionamento e a cooperação com agentes externos são essenciais para a absorção de conhecimento externo, que combinado ao conhecimento de base da empresa, possibilitou gerar novas capacidades de inovação sem a necessidade de substanciais dispêndios. Nestes termos, no plano das fontes de informação para absorção do conhecimento tecnológico ocorreu uma relativa diversificação. Em ordem de importância, destacaram-se as principais fontes de informação/conhecimento: $\left(1^{\circ}\right)$ "Clientes/consumidores"; $\left(2^{\circ}\right)$ "Redes de informação informatizadas"; $\left(3^{\circ}\right)$ "Fornecedores"; e, $\left(4^{\circ}\right)$ "Feiras e exposições".

Buscando aproximar as atividades, resultados e esforços para a inovação no segmento com os meios de aprendizado, a aquisição de M\&E e de software se relacionaram com o aprendizado das empresas no ato de fazer (learning by doing), e através do uso das novas e antigas técnicas e M\&E para produzir, que se 
desdobra em aprendizado no ato de usar (learning by using). Um seleto grupo de empresas (20\% do total) se relacionaram intensamente com a $\mathrm{P} \& \mathrm{D}$, que se desdobrou em aprendizado por meio da busca (learning by searching). Este processo possibilitou a elaboração de novos projetos e produtos, ou mesmo processos para produzi-los. Em conjunto, os três processos de aprendizado internos resultaram na geração de conhecimento/tecnologia endógena, apesar de o último apresentar maior capacidade para as firmas desenvolverem suas próprias trajetórias tecnológicas.

O relacionamento com "Clientes/consumidores" e "Fornecedores" são fontes de informação que podem ser absorvidas e incorporadas a partir do aprendizado que ocorre por meio da interação (learning by interacting). Na pesquisa realizada, este processo demonstrou ser fundamental para a capacitação tecnológica das firmas no setor. O conhecimento absorvido por via dos clientes difere dos fornecedores. Este ocorre por via de feedback de produtos, conhecimento dos processos dos clientes e sinalizações das necessidades do mercado; enquanto, com fornecedores o conhecimento absorvido provém de aquisição de M\&E e conhecimento sobre processos produtivos e de novos materiais decorrente das interações decorrentes.

Nestes termos, respondendo à pergunta de pesquisa, no plano dos processos produtivos os dados apontaram as necessidades de repasse tecnológico por via dos fornecedores, apesar da intensa elevação das próprias empresas como responsáveis pelas inovações, e aumento do indício de "novos processos para o mercado" nacional. A grande parte das inovações em processo foram novos apenas para as empresas, sendo assim, absorvidos por fontes externas, principalmente dos fornecedores de M\&E. No plano do desenvolvimento dos produtos, destacou-se a inovação de "novos produtos para o mercado nacional". As próprias empresas foram as responsáveis pelas inovações em produto, com aumento do indício da cooperação com outras empresas e instituições para tal. Sendo assim, apesar da necessidade de repasse tecnológico dos processos produtivos por parte dos fornecedores, foram crescentes o desempenho e os resultados em inovação em processo e principalmente produto por parte do segmento produtor de $M \& E$ da economia nacional.

Apesar de uma estrutura lógica baseada na aquisição de M\&E que possibilita transformações de processos produtivos, as empresas absorveram informações sobre produtos, outros processos e mercado junto aos clientes e fornecedores. E, a partir da utilização de uma série de outras atividades e fontes que possibilitaram a absorção de conhecimento, um seleto grupo de empresas do setor (22\% do total, que implementaram tanto inovações em produto como em processos) aumentaram suas capacidades de desenvolvimento tecnológico, que repercutiu sobre o desempenho inovativo do segmento como um todo.

Assim sendo, no plano da capacidade de inovação do setor, observou-se um aumento desta capacidade substancial, diante o posicionamento tecnológico ativo de um seleto grupo de empresas que influenciou os resultados gerais. Apesar de os dados não serem suficientes para confirmar ganhos de capacidade dinâmica por parte destas empresas, a análise dos processos de aprendizado indicou ganhos de capacidade de desenvolvimento tecnológico próprio (endógeno), com aumento da intensidade do learning by searching. Em conforme com a tendência de intensificação das relações com os parceiros da cadeia produtiva, intensificou-se o learning by interacting, enquanto as bases da transformação do conhecimento do setor de M\&E, o learning by using e o by doing, continuaram consolidados como os principais processos de aprendizado.

\section{REFERÊNCIAS BIBLIOGRÁFICAS}

ABDI (2011). O núcleo tecnológico da indústria brasileira. Agencia Brasileira de Desenvolvimento Industrial (ABDI), 2011.

ALÉM, A.C., PESSOA. R.M. O Setor de Bens de Capital e o Desenvolvimento Econômico: quais são os desafios? BNDES Setorial, Rio de Janeiro, n. 22, p. 71-88, set. 2005.

ARAÚJO, B. C. O núcleo tecnológico da indústria brasileira - bens de capital. IPEA. Brasília, 2011.

BANCO CENTRAL DO BRASIL. Relatórios anuais. Vários anos.

BERTASSO, B. F. Bens de capital seriados. Perspectiva de investimento em mecânica - Projeto PIB, UFRJ-IE. Campinas, jan. 2009. 
CAMPOS, B. C.; URRACA, A. R. Padrões Setoriais de Inovação na Indústria Brasileira. Revista Brasileira de Inovação, Rio de Janeiro (RJ), 8 (1), p.167-210, janeiro/junho, 2009.

COHEN, W.; LEVINTHAL, D. Absorptive capacity: a new perspective on learning an innovation. Administrative Science Quarterly, vol. 35, n.1, mar. 1990, p. 128-152.

EASTERBY-SMITH, M. GRACA, M. ANTONACOPOULOU, E. FERDINAND, J. Absorptive Capacity in Practice: An Empirical Examination of Zahra and George's Model. In: 6th International Organizational Knowledge, Learning and Capabilities Conference, Bentley College, Waltham, 2005.

FERNANDES, R. L. Capacitação e estratégias tecnológicas das empresas líderes da indústria têxtilconfecções no estado de Santa Catarina. Dissertação DE Mestrado em Economia - Programa de PósGraduação em Economia. Florianópolis, Universidade Federal de Santa Catarina - UFSC, 2008

HELFAT, C. E. and PETERAF, M. A. (2003). 'The dynamic resource-based view: capability lifecycles'. Strategic Management Journal, 24, 10, 997-1010.

INSTITUTO BRASILEIRO DE GEOGRAFIA E ESTATÍSTICA - IBGE Pesquisa de Inovação Tecnológica. RJ: IBGE, 2000, 2003, 2005, 2008 E 2011.

LUNDVALL, B. A. Why the new economy is a learning economy. Druid Working Paper, $\mathrm{n}^{\circ} .04-01$, Aalborg, 2001.

MALERBA, F. Learning by firms and incremental technical change. The Economic Journal, p. 845-859, July. 1992.

MARSILI, O.; VERSPAGEN, B. Technological regimes and innovation: Looking for regularities in Dutch manufacturing. ECIS, Eindhoven University of Technology, Netherlands, 2001.

MUROVEC, N.; PRODAN, I. Absorptive capacity, its determinants, and influence on innovation output: Cross-cultural validation of the structural model. Technovation, (in press), 2009.

PAVITT, K. Sectorial patterns of technical change: towards a taxonomy and a theory. Research Policy. no. 13, p. 343-737, 1984.

ROSA, A. C.; RUFFONI, J. Mensuração da capacidade absortiva de firmas que possuem interação com universidades. Revista Economia e Desenvolvimento, vol. 26, n. 1, 2014.

SAENZ, M. J., KNOPPEN, D., REVILLA, E. Absorptive Capacity in Buyer-supplier

Relationships: Empirical Evidence of Its Mediating Role. Journal of supply chain management, April, 2014.

SILVA, C. F. E SUZIGAN, W. Padrões setoriais de inovação da indústria de transformação brasileira. Estudos econômicos, vol.44 no.2 São Paulo abr./jun. 2014.

TEECE, D. J. 2007. Explicating dynamic capabilities: The nature and microfoundations of (sustainable) enterprise performance. Strategic Management Journal, 28: 1319-1350.

TEECE, D. J. 2014. A dynamic capabilities-based entrepreneurial theory of the multinational enterprise. Journal of International Business Studies (2014), 45, 8-37.

TEECE, D. J., \& Pisano, G. The dynamic capabilities of firms: An introduction. Industrial and Corporate Change, 3: 537-556, 1994.

TEECE, D. J., Pisano, G., \& Shuen, A. Dynamic capabilities and strategic management. Strategic Management Journal, 18: 509-533. 1997.

TEECE, D. Profiting from technological innovation. Research Policy, 15 (6), 285-305.1986.

TEIXEIRA, A. L .S; ROSA, A. C.; RUFFONI, J; RAPINI, M. S. Dimensões da capacidade de absorção, qualificação da mão de obra, $P \& D$ e desempenho inovativo. Revista Brasileira de Inovação, Campinas (SP), 15 (1), p. 139-164, janeiro/junho 2016.

WANG, C. L. and Ahmed, P. K. (2007). Dynamic capabilities: a review and research agenda. The International Journal of Management Reviews, 9 (1): 31-51.

VERMULM, R.; ERBER, F. Cadeia: bens de capital. Estudo da Competitividade de Cadeias Integradas no Brasil: impactos das zonas de livre comércio. UNICAMP-IE-NEIT, 2002. (Nota Técnica Final). VERMULM, R. A indústria de bens de capital seriados. Convênio CEPAL/IPEA. Dezembro de 2003. ZAHRA, S. A. E GEORGE, G. Absorptive capacity: A review, reconceptualization, and extension. Academy of Management Review, 27 (2): 185-203. 2002. 
ZAHRA, S. A., SAPIENZA, H. J.; DAVIDSSON, P. Entrepreneurship and Dynamic Capabilities: A Review, Model and Research Agenda. Journal of Management Studies 43(4):pp. 917-955, 2006. Accessed from http://eprints.qut.edu.au 